\title{
Effects of chromophore interaction in the spectroscopy of ketocyanine dyes with a central pyranone or pyridone fragment
}

\author{
Ludmila A. Shvedova, ${ }^{1, \dagger}$ Alexander S. Tatikolov, ${ }^{1}$ Vladimir I. Sklyarenko, ${ }^{1}$ \\ and Zhanna A. Krasnaya ${ }^{2}$ \\ ${ }^{1}$ Institute of Biochemical Physics, Russian Academy of Sciences, Kosygin Str. 4, 119991 Moscow, Russia \\ ${ }^{2}$ Institute of Organic Chemistry, Russian Academy of Sciences, Leninsky Pr. 47, 117913, Moscow, Russia
}

\begin{abstract}
The study is devoted to investigation of a number of ketocyanine dyes (polyenic $\omega, \omega^{\prime}-$ bisaminoketones) with a central pyranone or pyridone fragment and respective polymethine salts by UV-VIS absorption and NMR spectroscopies. It was found that replacement of bridging $\mathrm{O}$ atom with NMe group suppresses the chromophore interaction in the cross-conjugated ketone and corresponding tridecamethine salt. Furthermore, incorporation of meso-amino substituent into the polymethine chain of the salts with the central pyrylium fragment sharply decreases the chromophore interaction. In spite of dramatic differences between the absorption spectra of the ketocyanines containing O- or NMe- bridging fragment, ${ }^{13} \mathrm{C} \mathrm{NMR}$ spectra of these dyes are similar. A comparison of the differences between the chemical shifts of adjacent polymethine carbon atoms in the ${ }^{13} \mathrm{C}$ NMR spectra for these dyes point to stronger alternation of charges along the polymethine chain and, consequently, stronger chromophore interaction for the dye with the central pyrylium cycle. Flash photolysis experiments showed photoisomerization of the dyes with NMe bridging group to form long-lived isomeric form.
\end{abstract}

\section{INTRODUCTION}

Ketocyanine dyes (polyenic $\omega, \omega^{\prime}$-bisaminoketones) belong to bichromophoric cross-conjugated polyenes containing two polymethine chains. Due to simple structures, these compounds appeared to be convenient for modeling various photophysical and photochemical processes. Recently we have studied the photonics of a number of ketocyanines, both simple and having a central pyranone fragment [1-4]. Their spectral and photophysical properties can be well explained in terms of the theory of chromophore interaction based on dipole-dipole interaction. Conjugation between the dye chromophores has also a strong effect on the absorption spectra of ketocyanines [5-7]. It was revealed that the absorption bands of symmetrical ketocyanines (containing two aminopolyene fragments of the same length) are shifted bathochromically with respect to those of the unsymmetrical dye with the same total length of the polyene chain [1, 3]. In contrast to the linear ketocyanines, an additional short-wavelength band is observed in the absorption spectrum of the dyes in which the chromophores are arranged at an angle to each other $[2,4]$. The ratio of the intensities of these two absorption bands is related to the angle between the chromophores. In particular, if the angle is obtuse, the short-wavelength band is less intense than the long-wavelength one, while for acute

${ }^{\dagger}$ E-mail: shvedova@sky.chph.ras.ru angle, the opposite is true. In this work, we investigated the spectral and photophysical properties of a new group of ketocyanine dyes with a central pyridone fragment, as well as the polymethine salts with central pyrylium or pyridinium fragments based on corresponding ketocyanines.

\section{EXPERIMENTAL}

Ketocyanine dyes (polyenic $\omega, \omega^{\prime}$-bisaminoketones) with a central pyranone or pyridone fragment and corresponding polymethine salts studied in this work were synthesized as described earlier [8]. The structures of the dyes are presented in Scheme 1.

The absorption spectra of the dyes were measured on a Specord UV-VIS spectrophotometer. The fluorescence and fluorescence excitation spectra of the dyes were studied on an Aminco-Bowman spectrofluorimeter equipped with an R136 photomultiplier (the spectra were not corrected for spectral sensitivity of the spectrofluorimeter). The ${ }^{13} \mathrm{C}$ NMR spectra were measured on a Bruker AC-200 spectrometer (50.32 MHz). The study of photoisomerization and formation of the triplet states of dye molecules was performed using a conventional flash photolysis equipment (flash fwhm $7 \mu$ s with the energy $50 \mathrm{~J}$ ). Chloroform, toluene, and isopropanol (spectroscopic grade) were used as solvents. In the studies of the triplet states, the solutions were deoxygenated by freeze-pump-thaw cycles. 


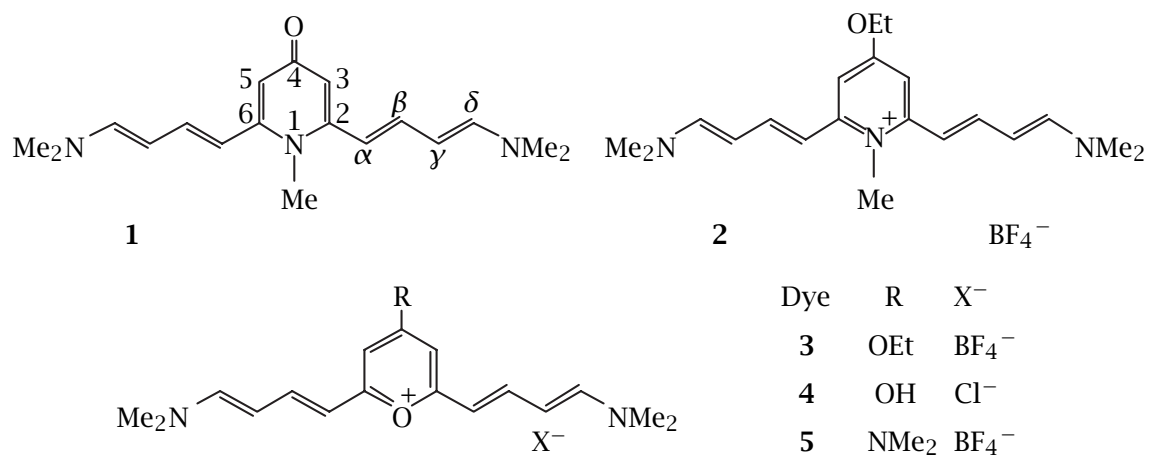

Scheme 1.

\section{RESULTS AND DISCUSSION}

The photophysical study of the newly synthesized bichromophoric compounds revealed a series of interesting features, whose investigation could contribute to the further development of the theory of chromophore interactions.

As mentioned above, the S-S absorption spectra of dye 6 consist of two bands: an intense short-wavelength band and a much less intense long-wavelength band (Figure 1).<smiles>CN/C=C/C=C/c1cc(=O)cc(/C=C/C=C/N(C)C)o1</smiles>

The positions of these bands, their intensity ratio, and the energy splitting $(\Delta v)$ between the $S_{1}$ and $S_{2}$ levels were explained in terms of interaction of two aminopolyenic chromophores in the dye molecule. The chromophores composing the dye (halves of dye 6 from the $\mathrm{NMe}_{2}$ fragment to the carbonyl group) are oriented at an acute angle with respect to each other [2-4]. We found that the replacement of the $\mathrm{O}$ atom in the pyranone ring of ketocyanine 6 by the NMe group (dye 1) led to a dramatic change in the absorption spectrum of the dye (Figure 1). Unlike compound 6, the absorption spectrum of ketocyanine $\mathbf{1}$ has only one band $\left(\lambda_{\max }=395 \mathrm{~nm}\right)$ located between two absorption bands of dye $6\left(\lambda_{\max }^{1}=357 \mathrm{~nm}\right.$ and $\left.\lambda_{\max }^{2}=461 \mathrm{~nm}\right)$; i.e., the chromophore interaction is not manifested (the fluorescence excitation spectrum of ketone $\mathbf{1}$ also consists of one band, like the absorption spectrum). Therefore, the presence of the NMe group in the pyridone fragment apparently precludes the chromophore interaction in compound 1. The oscillator strengths for dye $\mathbf{1}$ and $\mathbf{6}$ (summed over two bands) are the same and equal to 1.44 , so the two bands in the absorption spec-

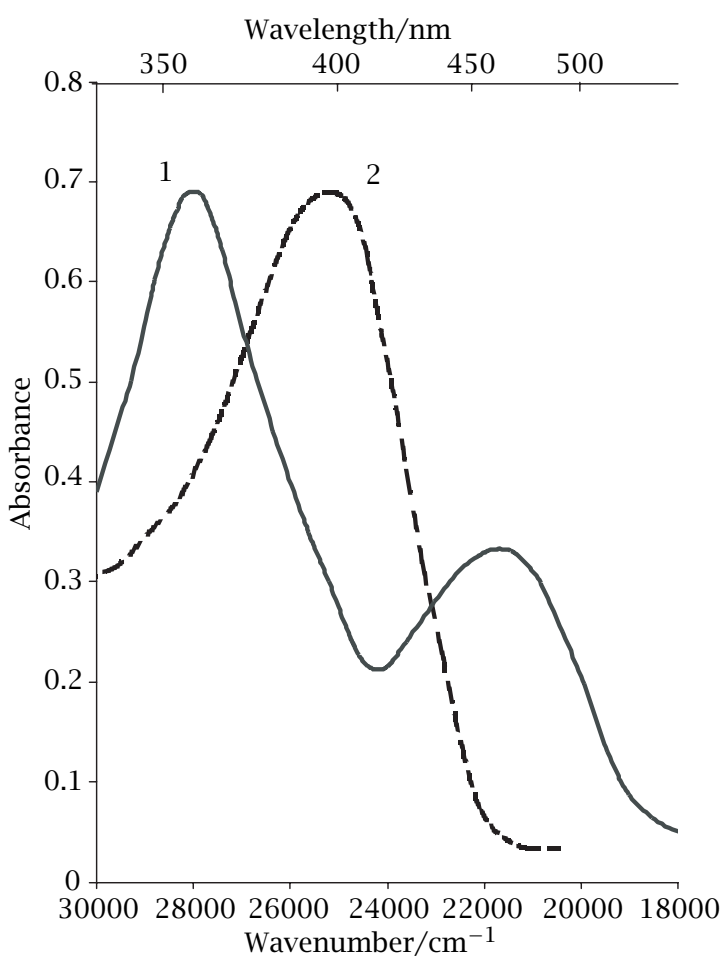

Figure 1. The absorption spectra of compounds $\mathbf{6}$ (1) and $\mathbf{1}$ (2) in $i-\mathrm{PrOH}$.

tra that are resolved in dye 6 coalesce to a single band in dye $\mathbf{1}$, which shows very weak chromophore interaction in dye $\mathbf{1}$. Since the absorption band of dye $\mathbf{1}$ is bathochromically shifted on going from toluene to chloroform and $i$-PrOH $\left(\lambda_{\max }=385,389\right.$, and $395 \mathrm{~nm}$, respectively), it is apparently a charge-transfer band (the long-wavelength absorption band of ketocyanine $\mathbf{6}$ also undergoes bathochromic shift with increasing solvent polarity [2]). In this case the carbonyl group acts as an electron acceptor and the amino groups serve as electron donors. The addition of trace amounts of acid $\left(C_{\mathrm{HCl}} \approx 10^{-6} \mathrm{moll}^{-1}\right)$ to a solution of dye 1 leads 
to a sharp change in its absorption spectrum: namely, the intensity of the initial band $\left(\lambda_{\max }=395 \mathrm{~nm}\right.$ in $i$ PrOH) decreases and a new band at $\lambda_{\max }=469 \mathrm{~nm}$ with a shoulder $\lambda_{\max }=390 \mathrm{~nm}$ appears. Apparently the latter band corresponds to the protonated form of dye 1 (PF). An isosbestic point, which is observed in the absorption spectra in the course of titration of ketocyanine $\mathbf{1}$ with acid, indicates that there is a simple equilibrium between the starting and protonated forms (Figure 2). The addition of small amounts of diethylamine restores the initial spectral pattern, which is an evidence for the reversibility of the prototropic equilibrium Dye $+\mathrm{H}^{+} \rightleftarrows \mathrm{DyeH}^{+}$(Figure 3 ).<smiles>C=CC=Cc1cc(O)cc(C=CC=CN(C)C)[n+]1C</smiles>

The absorption spectrum of $\mathbf{P F}$ is similar to that of polymethine salt 2 (Figure 4). A slight bathochromic shift in the spectrum of salt 2 compared to the spectrum of $\mathbf{P F}$ is apparently associated with the electronreleasing effect of the ethyl group at the $\mathrm{O}$ atom. This indicates that ketocyanine $\mathbf{1}$ is protonated at the carbonyl group of the dye to form the corresponding polymethine salt (protonation of simple pyrones proceeds analogously) [9].

The absorption spectra of $\mathbf{P F}$ and salt 2 differ sharply from the spectra of analogous polymethine salts 3-5 containing the central pyrylium fragment, which has been described earlier [3, 4]. Two bands in the spectrum of salts 3-5 were attributed to the interaction between the chromophores (halves of the molecule) oriented at an acute angle. The absorption bands of PF and salt $\mathbf{2}$ are substantially shifted toward the shortwavelength region $\left(\lambda_{\max }=469\right.$ and $484 \mathrm{~nm}$ for PF and 2 , respectively) with respect to the long-wavelength band of salts 3-5 ( $\lambda_{\max }=609$ and $592 \mathrm{~nm}$ for 3 and 4 , respectively). Furthermore, the second (more intense) short-wavelength band observed in the spectrum of salts 3-5 is weakly manifested in the spectra of PF and salt 2 (Figure 5): the spectra have only a shortwavelength shoulder at $\lambda_{\max }=380-390 \mathrm{~nm}$ and an intense band at $470-480 \mathrm{~nm}$. Since the shift of the bands (spectral band splitting $\Delta v$ ) caused by the chromophore interaction depends on the energy of this interaction, it can be concluded that this interaction in PF and salt 2 is much weaker than that in salts $\mathbf{3 - 5}$, that is, the chromophore interaction is sharply weakened by the central NMe group, like in the case of ketocyanine $\mathbf{1}$.

In spite of the fact that the absorption spectrum of ketocyanine $\mathbf{6}$ differs substantially from that of $\mathbf{1}$

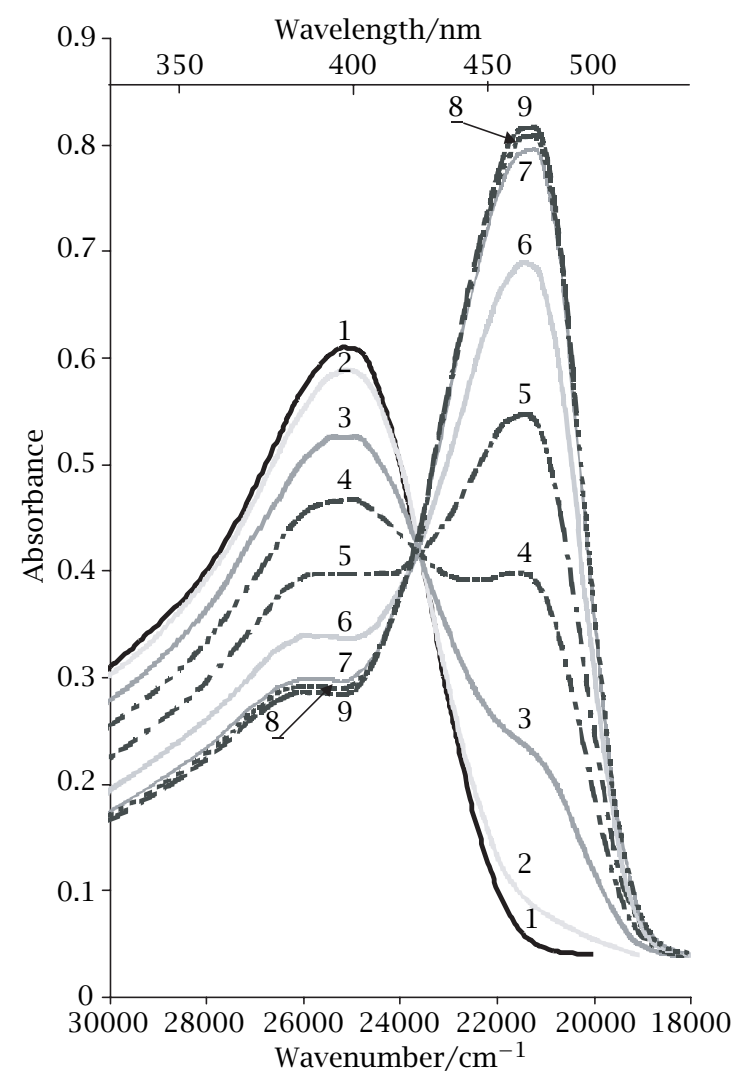

Figure 2. Titration of ketocyanine $\mathbf{1}$ with acid in $i$-PrOH: (1) $c_{\mathrm{HCl}}=0 ;(2) c_{\mathrm{HCl}}=3.84 \times 10^{-6} \mathrm{M}$; (3) $c_{\mathrm{HCl}}=7.7 \times 10^{-6} \mathrm{M}$; (4) $c_{\mathrm{HCl}}=1.15 \times 10^{-5} \mathrm{M}$; (5) $c_{\mathrm{HCl}}=1.54 \times 10^{-5} \mathrm{M}$; (6) $c_{\mathrm{HCl}}=$ $1.92 \times 10^{-5} \mathrm{M}$; (7) $c_{\mathrm{HCl}}=2.31 \times 10^{-5} \mathrm{M}$; (8) $c_{\mathrm{HCl}}=2.69 \times$ $10^{-5} \mathrm{M} ;(9) c_{\mathrm{HCl}}=4.69 \times 10^{-5} \mathrm{M}$.

(see Figure 1), their ${ }^{13} \mathrm{C}$ NMR spectra are similar (see Table 1). The absorption spectra of bichromophoric ketocyanines are determined by the chromophore interaction (which influences the positions of the $S_{1}$ and $S_{2}$ levels), whereas the ${ }^{13} \mathrm{C}$ NMR spectra reflect the electron density distribution within the polymethine chains of both chromophores. Therefore, one would hardly expect that a change in this interaction upon the replacement of the bridging $\mathrm{O}$ atom outside the chromophores by the NMe group would drastically change the electron density distribution on the $\mathrm{C}$ atoms of the polymethine chains inside the chromophores, because the chromophore interaction via conjugation through the carbonyl group is much weaker than the $\pi$-electron conjugation within each chromophore. This is reflected in similar values of the chemical shifts in the ${ }^{13} \mathrm{C}$ NMR spectra of dyes $\mathbf{6}$ and $\mathbf{1}$ in chloroform (see Table 1). Nevertheless, the differences between the chemical shifts of the adjacent polymethine carbon atoms $(\alpha-\mathrm{C})-(\mathrm{C}-2)$ and $(C-2)-(C-3)$ (close to the carbonyl group and the substituend (O- or $\mathrm{N}$-atom)) for dye 6 are somewhat larger than those for the dye $\mathbf{1}$ and are closer to the 


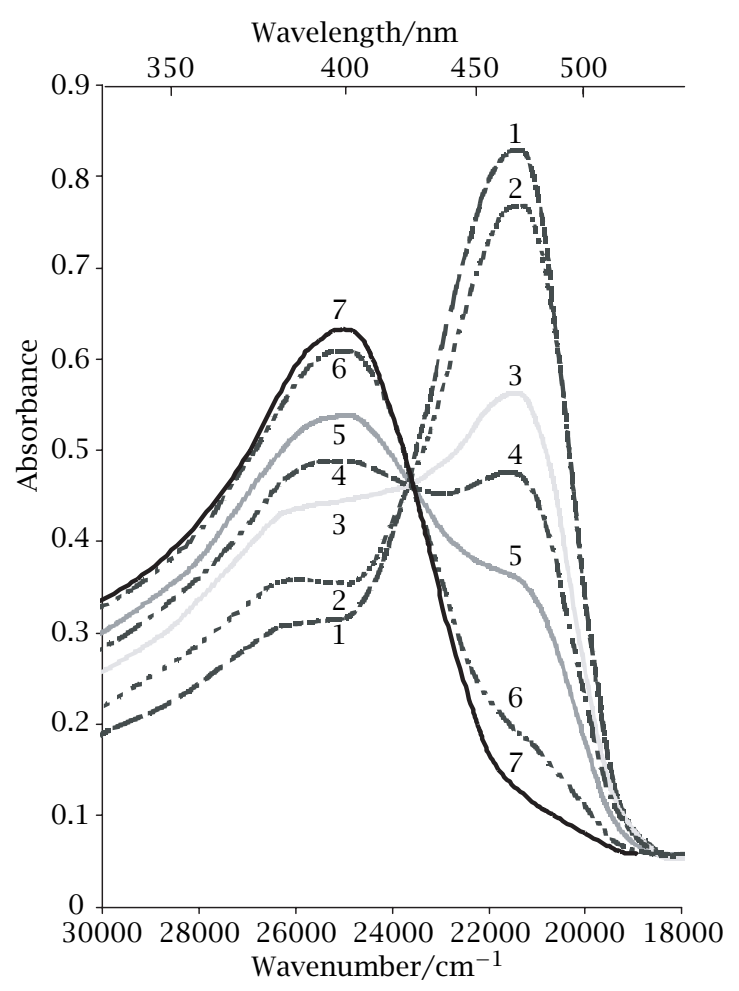

Figure 3. Titration of ketocyanine 1 with dietylamine (DEA) in the presence of $\mathrm{HCl}$ acid $\left(c_{\mathrm{HCl}}=2.3 \times 10^{-5} \mathrm{M}\right)$ in $i$-PrOH: (1) $c_{\mathrm{DEA}}=0$; (2) $c_{\mathrm{DEA}}=2.23 \times 10^{-5} \mathrm{M}$; (3) $c_{\mathrm{DEA}}=3.01 \times$ $10^{-5} \mathrm{M}$; (4) $c_{\mathrm{DEA}}=3.74 \times 10^{-5} \mathrm{M}$; (5) $c_{\mathrm{DEA}}=4.47 \times 10^{-5} \mathrm{M}$; (6) $c_{\mathrm{DEA}}=5.24 \times 10^{-5} \mathrm{M} ;(7) c_{\mathrm{HCl}}=0, c_{\mathrm{DEA}}=0$.

corresponding values for salt 3 having equalized polymethine chain bonds (Table 1). Since chemical shifts for polymethine carbons in ${ }^{13} \mathrm{C}$ NMR spectra reflect $\pi$ electron density on the corresponding atoms, the differences between the chemical shifts of adjacent polymethine carbon atoms could reflect the alternation of charges on polymethine carbons, which is maximum for the polymethine salt. The similar features were observed earlier in ${ }^{13} \mathrm{C}$ NMR spectra for some ketocyanines and corresponding polymethine salts $[10,11]$.

Thus, a comparison of the ${ }^{13} \mathrm{C}$ NMR spectra of dyes 6 and $\mathbf{1}$ points to stronger alternation of charges along the polymethine chain and, consequently, stronger chromophore interaction for dye $\mathbf{6}$ with the central pyranone cycle.

A comparison of chemical shifts for dye 6 in two solvents (methanol and chloroform) shows an increase in alternation of charges on the $\mathrm{C}$ atoms of polymethine chain with growing solvent polarity. This can be explained by strong solvatochromism of dye $\mathbf{6}$ (as for usual ketocyanines [11]): its absorption spectrum is shifted bathochromically with an increase in solvent polarity. In contrast, salt 3 exhibits small changes in ${ }^{13} \mathrm{C}$ chemical shifts with changing solvent polarity
(Table 1). This is in agreement with weak solvatochromism of polymethine salt 3 .

It was of interest to compare the absorption spectra of salts 3, 4 and salt 5 . The spectrum of salt 3 is similar to that of salt 4 (a small bathochromic shift of the bands in the spectrum of $\mathbf{3}$ is apparently attributed to the electron-releasing effect of the central ethyl group), whereas the spectrum of salt 5 much more substantially differs from the spectra of 3 and 4 . First, the band splitting $\Delta v_{2}$ in the spectrum of salt $\mathbf{5}$ is much smaller than that observed in the spectra of $3\left(\Delta v_{1}\right)$ and 4 , which is indicative of weakening the chromophore interaction in 5 (Figure 5). This is apparently a consequence of the perturbing electronic effect of the meso-amino group on the polymethine chromophore of the salt. An analogous effect was also observed for meso-aminosubstituted thiacarbocyanines; namely, the insertion of the meso-amino group leads to broadening and a hypsochromic shift in the absorption spectrum of the dye [12]. A perturbing effect of the amino group responsible for a sharp weakening of the chromophore interaction was also observed in salts 2 and PF. The elimination of the chromophore interaction in ketocyanine $\mathbf{1}$ is apparently explained in the same way.

The absorption spectra of polymethine salts 3-5 have bands at $\sim 380$ and 500-600 nm along with an additional band at $\sim 430 \mathrm{~nm}$, which is observed as a small plateau in the spectra of salts 3 and 4 and is much more pronounced in the spectrum of salt 5 . This band is apparently attributed to excitation localized on the central pyrylium fragment, because the long-wavelength absorption band of the triphenylpyrylium cation is located in this region. The presence of the amino group in salt $\mathbf{5}$ increases the intensity of this band.

Upon direct photoexcitation of air-saturated solutions of dye $\mathbf{1}$ and salt $\mathbf{2}$ with NMe bridging group, long-lived photoisomers (independent of the presence of oxygen and dye concentration) are formed in the absorption regions $370-460$ and $480-510 \mathrm{~nm}$, respectively. The differential absorption spectra of the photoisomers are shown in Figure 6. Their characteristic lifetimes are very long (more than $200 \mathrm{~s}$ ) even at elevated temperatures $\left(\sim 80^{\circ} \mathrm{C}\right)$, which is in agreement with the data on the photoisomers of other ketocyanines [12]. The apparent lifetimes of the photoisomers were found to depend on the intensity of probing light due to an additional channel of photoisomer decay photostimulated by the probing light. So it was only possible to estimate roughly the rate constants of back isomerization $\left(k_{\text {isom }} \leq \mathbf{5} \times 10^{-3} \mathrm{~s}^{-1}\right)$ for ketocyanine $\mathbf{1}$ and salt 2 . In contrast with dyes 1 and 2 , the quantum yield of photoisomerization process for dye $\mathbf{6}$ with pyranone cycle is very low (less than $0.5 \%$ ). Note that $k_{\text {isom }}$ for polymethine salts derived from usual ketocyanines are much greater than that estimated for salt 2 (for example, for salt $7 k_{\text {isom }}=1.4 \times 10^{4} \mathrm{~s}^{-1}$ ). 


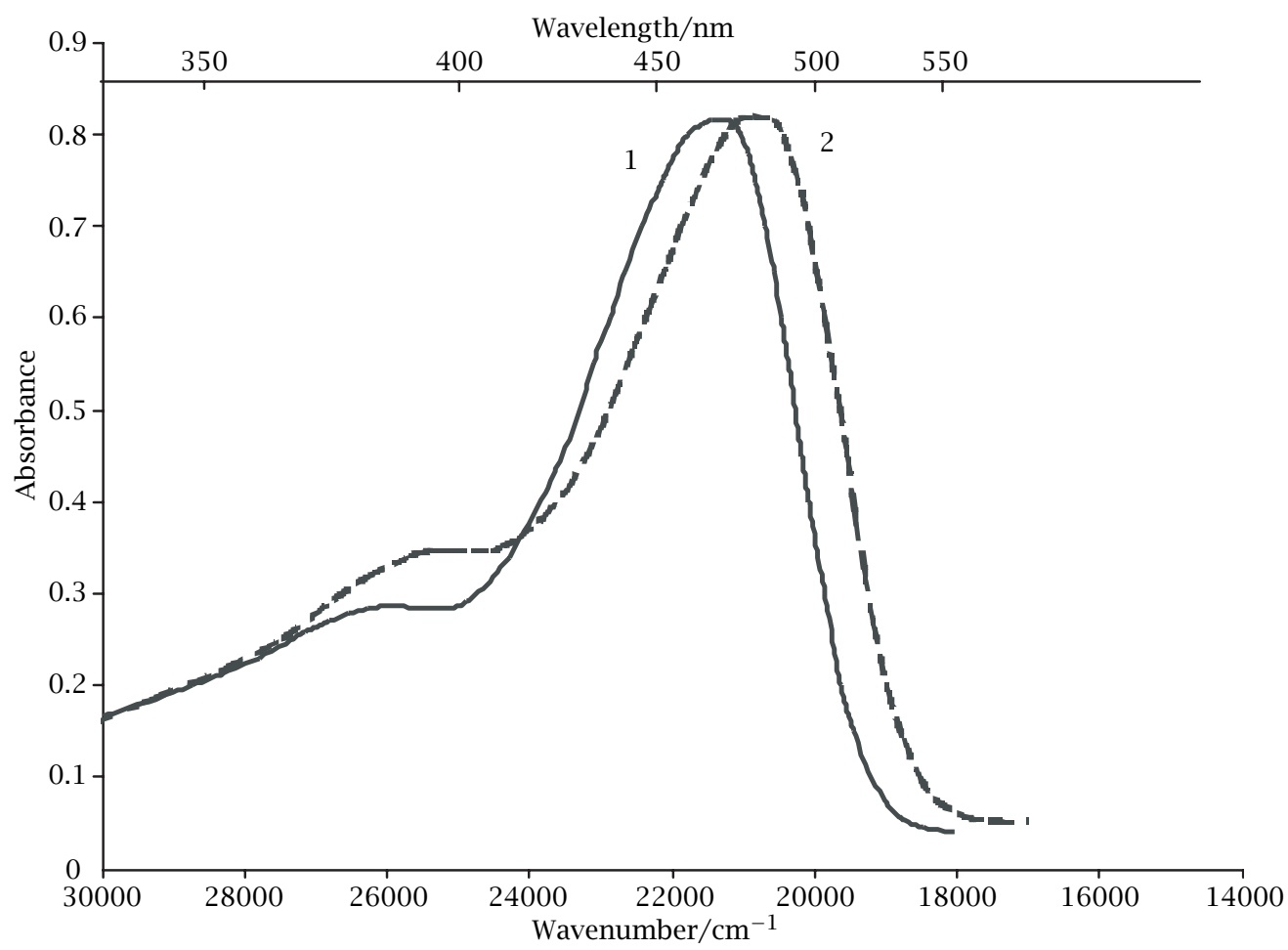

Figure 4. The absorption spectra of the protonated form of dye $\mathbf{1}$ (PF) (1) and salt 2 (2) in $i$-PrOH.

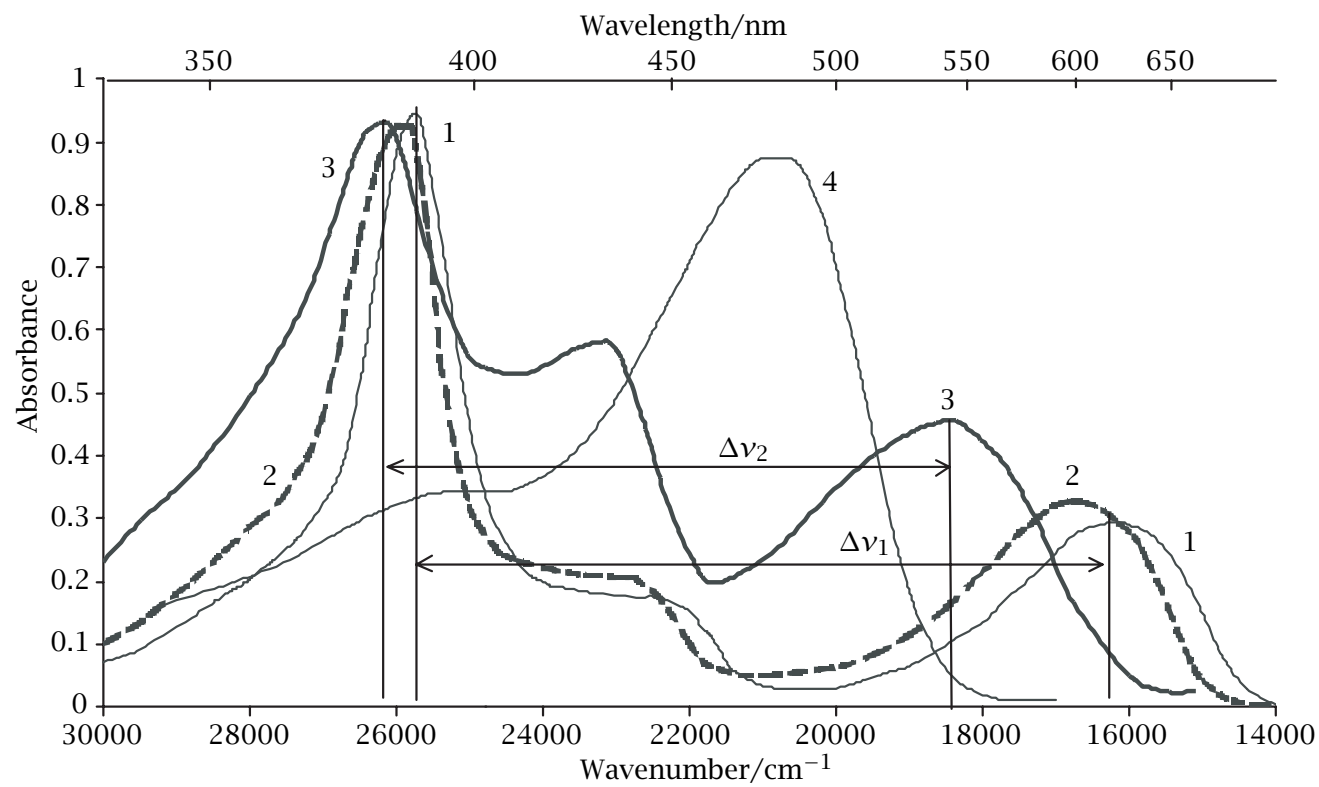

Figure 5. The absorption spectra of salts 3 (1); 4 (2); 5 (3) and 2 (4) in $i-\mathrm{PrOH}$. 
Table $1 .{ }^{13} \mathrm{C}$ NMR chemical shifts for dyes 1, 6 and 3 and the differences between the chemical shifts of adjacent polymethine carbon atoms.

\begin{tabular}{|c|c|c|c|c|c|}
\hline \multicolumn{6}{|c|}{ Dye 1 (in chloroform) } \\
\hline$\delta$-C & $\gamma-\mathrm{C}$ & $\beta-C$ & $\alpha-\mathrm{C}$ & $\mathrm{C} 2$ & $\mathrm{C} 3$ \\
\hline 147.7 & 97.6 & 139 & 111.4 & 151.9 & 110 \\
\hline$(\delta-\mathrm{C})-(\gamma-\mathrm{C})$ & $(\beta-C)-(\gamma-C)$ & $(\beta-C)-(\alpha-C)$ & $(\alpha-C)-(C-2)$ & $(C-2)-(C-3)$ & \\
\hline 50.1 & 41.4 & 27.6 & 40.5 & 41.9 & \\
\hline \multicolumn{6}{|c|}{ Dye 6 (in chloroform) } \\
\hline$\delta$-C & $\gamma-\mathrm{C}$ & $\beta$-C & $\alpha-C$ & $\mathrm{C} 2$ & $\mathrm{C} 3$ \\
\hline 148.54 & 97.58 & 137.64 & 110.1 & 163.1 & 108.32 \\
\hline$(\delta-\mathrm{C})-(\gamma-\mathrm{C})$ & $(\beta-C)-(\gamma-C)$ & $(\beta-C)-(\alpha-C)$ & $(\alpha-C)-(C-2)$ & $(C-2)-(C-3)$ & \\
\hline 50.96 & 40.06 & 27.54 & 53 & 54.78 & \\
\hline \multicolumn{6}{|c|}{ Dye 6 (in methanol) } \\
\hline$\delta$-C & $\gamma-\mathrm{C}$ & $\beta-C$ & $\alpha-C$ & $\mathrm{C} 2$ & C3 \\
\hline 152.31 & 99.45 & 142.39 & 109.59 & 167 & 107.33 \\
\hline$(\delta-\mathrm{C})-(\gamma-\mathrm{C})$ & $(\beta-C)-(\gamma-C)$ & $(\beta-C)-(\alpha-C)$ & $(\alpha-C)-(C-2)$ & $(C-2)-(C-3)$ & \\
\hline 52.86 & 42.94 & 32.8 & 57.41 & 59.67 & \\
\hline \multicolumn{6}{|c|}{ Salt 3 (in chloroform) } \\
\hline$\delta$-C & $\gamma-\mathrm{C}$ & $\beta-C$ & $\alpha-C$ & $\mathrm{C} 2$ & $\mathrm{C} 3$ \\
\hline 157.549 & 96.273 & 148.32 & 104.43 & 167.8 & 99.919 \\
\hline$(\delta-\mathrm{C})-(\gamma-\mathrm{C})$ & $(\beta-C)-(\gamma-C)$ & $(\beta-C)-(\alpha-C)$ & $(\alpha-C)-(C-2)$ & $(C-2)-(C-3)$ & \\
\hline 61.276 & 52.047 & 43.894 & 63.378 & 67.885 & \\
\hline \multicolumn{6}{|c|}{ Salt 3 (in DMSO) } \\
\hline$\delta$-C & $\gamma-\mathrm{C}$ & $\beta-C$ & $\alpha-\mathrm{C}$ & $\mathrm{C} 2$ & C3 \\
\hline 156.3 & 96.6 & 146.3 & 104.1 & 167 & 99.7 \\
\hline$(\delta-\mathrm{C})-(\gamma-\mathrm{C})$ & $(\beta-C)-(\gamma-C)$ & $(\beta-C)-(\alpha-C)$ & $(\alpha-C)-(C-2)$ & $(C-2)-(C-3)$ & \\
\hline 59.7 & 49.7 & 42.2 & 62.9 & 67.3 & \\
\hline
\end{tabular}

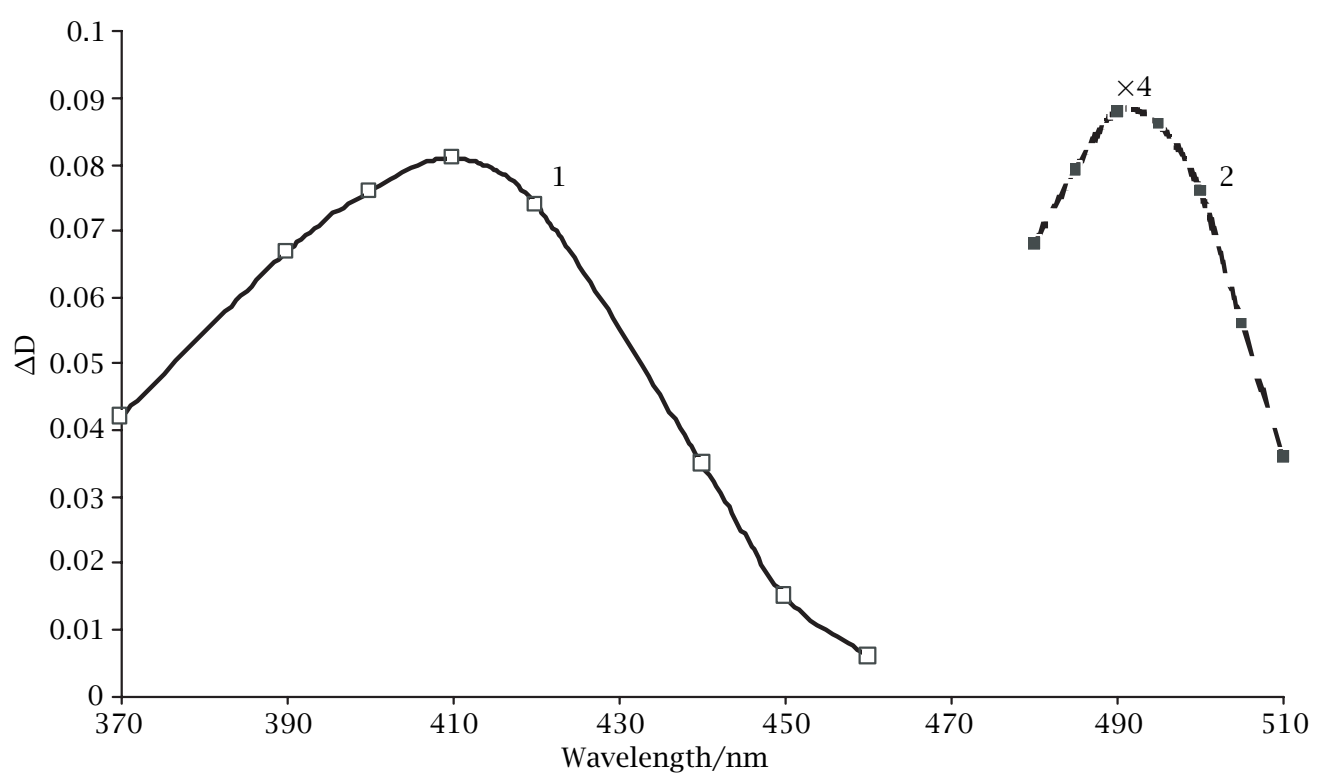

Figure 6. The differential absorption spectra of the photoisomers in $i$-PrOH: (1) for dye 1; (2) for salt 2. 


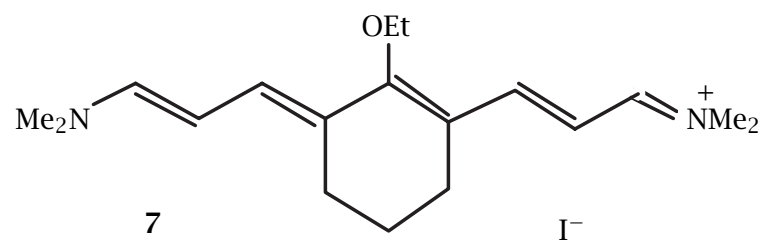

This is the consequence of complete equalization of polyenic bonds in the molecules of polymethine salts due to conjugation of polyenic $\pi$-electrons. In contrast, ketocyanines, which have alternating bonds in the polyenic chain, exhibit very small values of $k_{\text {isom }}$ [13]. Since salt 2 also has low $k_{\text {isom }}$, we may reasonably suppose that the polyenic bonds in its molecule are alternating. It could be due to disruption of conjugation along the polyenic chain caused by the central amino substituent (the perturbing effect of the amino group observed above in the absorption spectra of salt 2 and PF in comparison with salts 3 and 4).

Upon photoexitation of the dyes in deaerated solution, the triplet state of dye $\mathbf{5}$ is observed, but the quantum yield of $\mathrm{S}_{1} \rightarrow \mathrm{T}$ intersystem crossing process is low $(\sim 1 \%)$. The rate constant of the triplet state decay is $\sim 3 \times 10^{3} \mathrm{~s}^{-1}$.

\section{CONCLUSIONS}

The study has shown that the presence of NMe group in the central bridging cycle suppresses interaction between the chromophores in ketocyanine dyes and decreases chromophore conjugation in the corresponding polymethine salts. Addition of traces of acids leads to reversible protonation of the central carbonyl group of the ketocyanine with pyridone fragment, showing high basicity of the dye (addition of an amine shifts the protonation equilibrium to formation of the initial form of the dye). ${ }^{13} \mathrm{C}$ NMR data confirm that the replacement of the central bridging $\mathrm{O}$ atom with NMe group decreases chromophore interaction in the ketocyanine dyes. It has been found that $k_{\text {isom }}$ for the polymethine salt derived from the ketocyanine with a central pyridone fragment differs sharply from usual values of $k_{\text {isom }}$ for simple polymethine salts. It could be due to the perturbing effect of the central amino substituent on the conjugation along the polyenic chain of salt 2 .

\section{ACKNOWLEDGMENTS}

This work was supported by the Russian Foundation for Basic Research (02-03-32924 and 05-03-32775).

Basic Research (02-03-32924 and 05-03-32775).

\section{REFERENCES}

[1] L. A. Shvedova, Yu. E. Borisevich, A. S. Tatikolov, V. A. Kuz'min, and Zh. A. Krasnaya, Izv. Akad. Nauk SSSR, Ser. Khim. 4 (1983), 819 [Bull. Acad. Sci. SSSR, Div. Chem. Sci. 32 (1983), 747 (Engl. Transl.)].

[2] Zh. A. Krasnaya, Yu. V. Smirnova, A. S. Tatikolov, and V. A. Kuz'min, Izv. Akad. Nauk, Ser. Khim. 7 (1999), 1340 [Russ. Chem. Bull. 48 (1999), 1329 (Engl. Transl.)].

[3] A. S. Tatikolov, Zh. A. Krasnaya, L. A. Shvedova, and V. A. Kuz'min, Int. J. Photoenergy 2 (2000), 23.

[4] A. S. Tatikolov, Zh. A. Krasnaya, L. A. Shvedova, and V. A. Kuz'min, Zh. Nauchn. PrikI. Fotografii 46 (2001), 34 [Sci. Appl. Photo 43 (2001), 39 (Engl. Transl.)].

[5] A. I. Kiprianov, Usp. Khim. 40 (1971), 1283 [Russ. Chem. Rev., 1971 (Engl. Transl.)].

[6] Yu. E. Borisevich, Dokl. Akad. Nauk SSSR 241 (1978), 1359 [Dokl. Chem., 1978 (Engl. Transl.)].

[7] A. N. Terenin, Fotonika molekul krasitelei, [Photonics of Dye Molecules] Nauka, Leningrad, 1967 (in Russian).

[8] Zh. A. Krasnaya, Yu. V. Smirnova, L. A. Shvedova, A. S. Tatikolov, and V. A. Kuz'min, Izv. Akad. Nauk, Ser. Khim. 9 (2003), 1920 [Russ. Chem. Bull. 9 (2003), 2029 (Engl. Transl.)].

[9] A. I. Tolmachev, M. Yu. Kornilov, L. M. Shulezhko, and A. V. Turov, Teor. Eksp. Khim. 11 (1975), 556 [Theor. Exp. Chem. 11 (1975), (Engl. Transl.)].

[10] L. A. Shvedova, A. S. Tatikolov, Zh. A. Krasnaya, A. R. Bekker, and V. A. Kuz'min, Izv. Akad. Nauk SSSR, Ser. Khim. 1 (1988), 61 [Bull. Acad. Sci. USSR, Div. Chem. Sci. 37 (1988), 52 (Engl. Transl.)].

[11] L. A. Shvedova, A. S. Tatikolov, V. A. Kuz'min, Zh. A. Krasnaya, and A. R. Bekker, Dokl. Akad. Nauk SSSR 276, 654 [Dokl. Phys. Chem. 276 (1984), 457 (Engl. Transl.)].

[12] T. Kunisawa, T. Sato, Y. Yonezawa, and G. V. Popova, Thin Solid Films 311 (1997), 267.

[13] L. A. Shvedova, A. S. Tatikolov, Zh. A. Krasnaya, A. R. Bekker, and V. A. Kuz'min, Izv. Akad. Nauk SSSR, Ser. Khim. 1 (1990), 1514 [Bull. Acad. Sci. USSR, Div. Chem. Sci. 37 (1990), 52 (Engl. Transl.)]. 


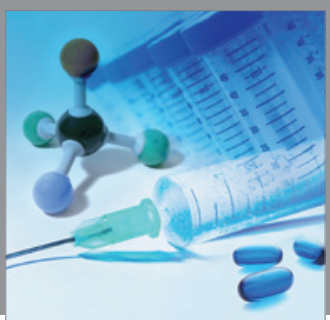

International Journal of

Medicinal Chemistry

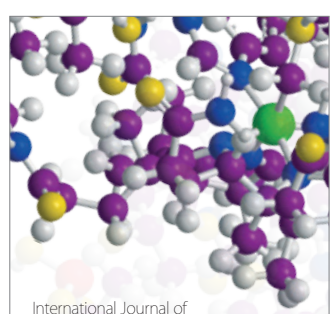

Carbohydrate Chemistry

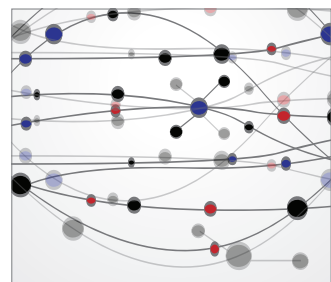

The Scientific World Journal
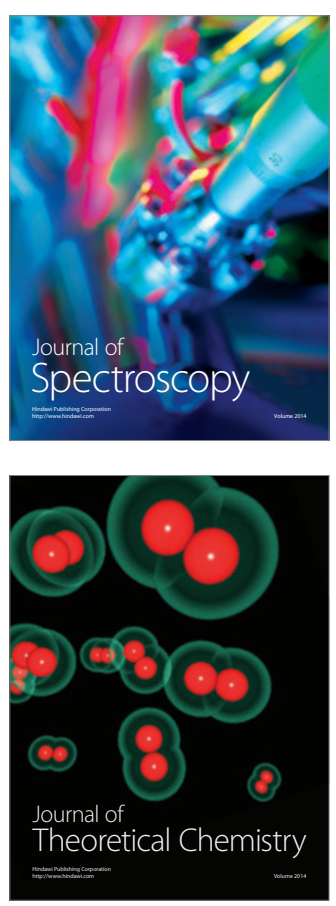
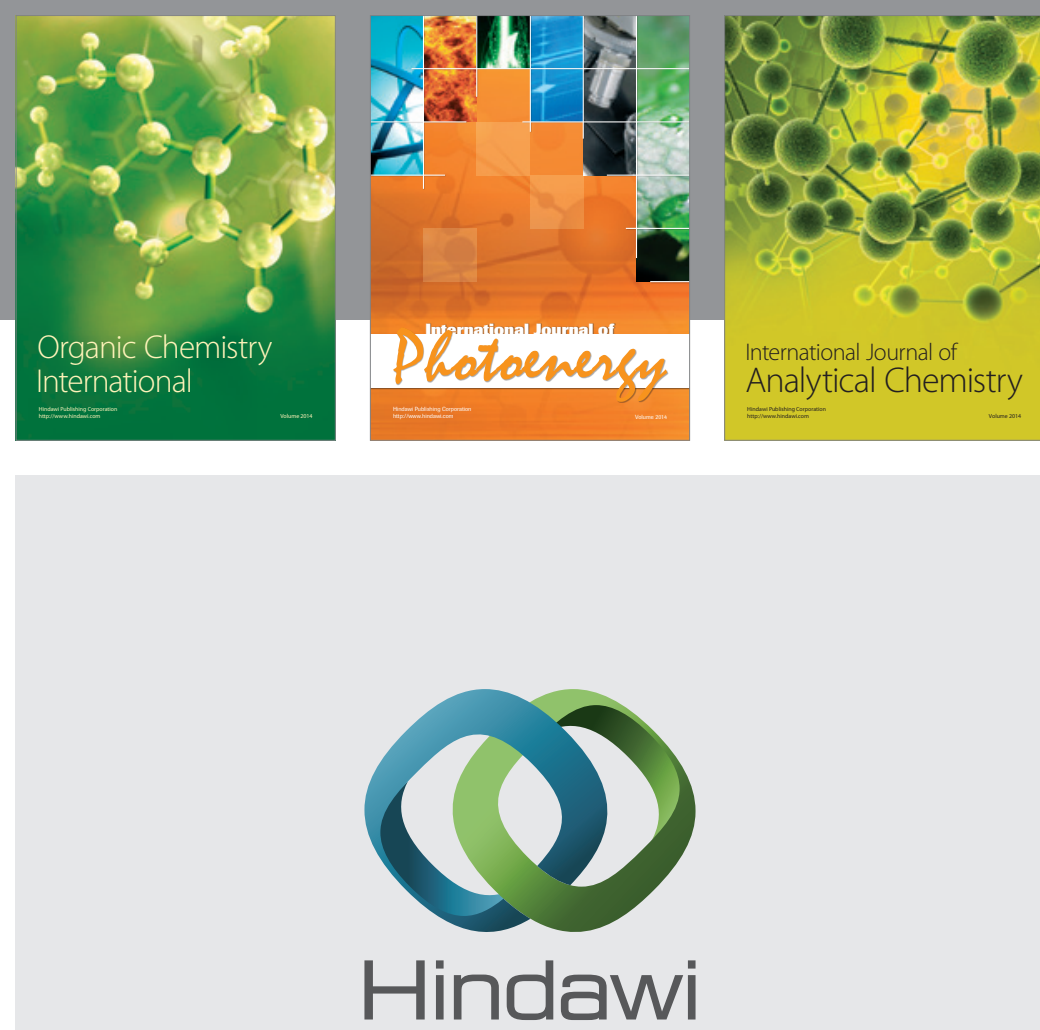

Submit your manuscripts at

http://www.hindawi.com
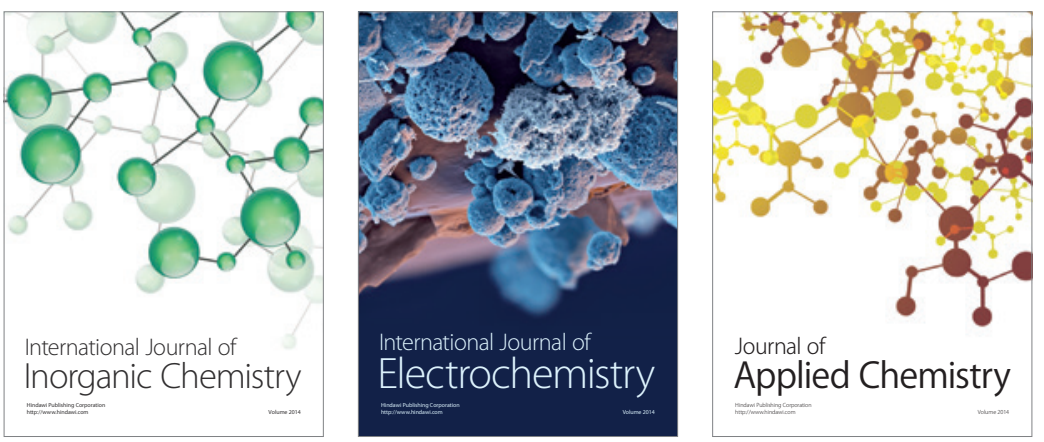

Journal of

Applied Chemistry
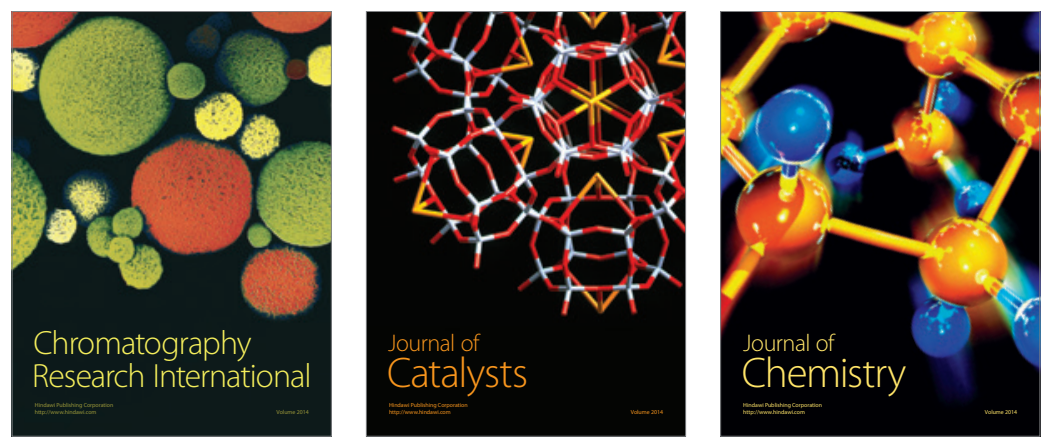
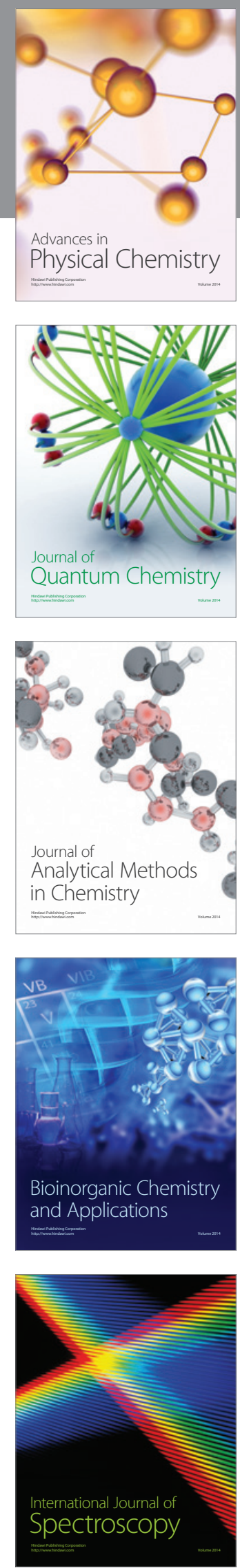